\title{
Geostrophic currents and kinetic energies in the Black Sea estimated from merged drifter and satellite altimetry data
}

\author{
M. Menna and P.-M. Poulain \\ Istituto Nazionale di Oceanografia e Geofisica Sperimentale - OGS, Trieste, Italy \\ Correspondence to: M. Menna (mmenna@ogs.trieste.it) \\ Received: 30 July 2013 - Published in Ocean Sci. Discuss.: 4 September 2013 \\ Revised: 30 January 2014 - Accepted: 4 February 2014 - Published: 11 March 2014
}

\begin{abstract}
Drifter measurements and satellite altimetry data are merged to reconstruct the surface geostrophic circulation of the Black Sea in the period 1999-2009. This combined data set is used to estimate pseudo-Eulerian velocity statistics for different time periods. Seasonal and interannual variability of currents and kinetic energy fields are described with particular attention to the mesoscale and sub-basin coastal eddies. The mean currents are generally stronger in winter and enhanced speeds are observed in the period 2002-2006. The most intense activity of sub-basin Batumi Eddy occurs in summer with greater speeds and dimensions in 2006 and 2008. The sub-basin Sevastopol Eddy is generated in spring from a meander of the Rim Current. Mesoscale eddies located along the Anatolia, Caucasus and Crimea coasts are permanent, quasi-permanent or intermittent features and can interact and merge with each other, showing high values of kinetic energy.
\end{abstract}

\section{Introduction}

Surface currents contribute significantly to the distribution of hydrological properties, nutrients, pollution and other kinds of dissolved and suspended particles, among adjacent coastal regions and between coastal and open-ocean regions. Their assessment assume an important role in the densely inhabited coastal areas and semi-enclosed basins, where pollutants and contaminants are produced and discharged in large amounts. In this context, the Black Sea (BS), with a catchment area that cover extended areas of Europe and Asia (Stanev, 2005), represents a good example of marginal semi-enclosed basin, characterised by a limited water exchange with the other basins and an intense anthropic activity and river discharge.
The upper-layer dynamics of the BS is conventionally described as the combination of a basin-scale cyclonic boundary current over the continental slope (e.g. Oguz et al., 1992), cyclonic gyres in the basin interior (Korotaev et al., 2001) and quasi-stationary or recurrent anticyclonic eddies along the coast (Korotaev et al., 2003). The interaction among these different and multi-scaled features contribute to the mixing of coastal water with the open sea and results in a high spatiotemporal variability of the current field.

The most exhaustive descriptions of the interannual, seasonal and mesoscale variability in the BS were obtained with satellite altimetry products (Stanev et al., 2000; Korotaev et al., 2001, 2003) and Lagrangian observations (Poulain et al., 2005). The BS surface circulation has a strong seasonal variability, with intensification of the cyclonic alongslope Rim Current (RC) in winter and attenuation in summer and fall (Stanev et al., 2000; Korotaev et al., 2001; Poulain et al., 2005). The organised winter circulation gradually disintegrates into a series of interconnecting eddies in summer and fall, when the RC exhibits more pronounced and complex mesoscale activity (Korotaev et al., 2003). The mesoscale variations are strongest in the RC and in large quasi-permanent nearshore sub-basin-scale anticyclonic eddies (Stanev et al., 2000), such as the Batumi Eddy (BE) and the Sevastopol Eddy (SE), and off the Crimean Peninsula (Korotaev et al., 2001). Mesoscale eddies induce the process of exchange between shelf and open sea waters (Shapiro et al., 2010). The BE has a seasonal modulation with intense cyclonic circulation in winter and weaker (sometimes anticyclonic) rotation in the summer-fall period (Stanev et al., 2000; Poulain et al., 2005). The SE is characterised by low seasonal variability and has large sea level oscillations at the inter- and intraannual scales. The interannual variability has 
the strongest signature in the southeastern BS (Stanev et al., 2000). Globally, the kinetic energy levels were found higher in winter-spring and lower in summer-fall periods (Poulain et al., 2005).

Both drifter and satellite data have been recognised as most useful to observe variation of sea-surface velocity fields (Uchida and Imawaki, 2003), although they present some drawbacks. Altimetry data are regularly sampled in space and time but they are generally low-pass filtered, interpolated and inaccurate in coastal areas and in the resolution of mesoscale features. In contrast, drifter data yield an accurate but irregular spatial and temporal sampling of the surface currents (Menna et al., 2012), therefore the resulting descriptions of surface circulation can be biased and strongly dependent on the specific data distribution (Poulain et al., 2012).

To overcome the aforementioned limitations, drifter and altimetry data can be combined to provide a more accurate representation of the mean circulation with respect to the computation performed from each data set alone (Centurioni et al., 2008; Poulain et al., 2012). The combination of these two independent data sets has already been used to produce quantitative descriptions of the circulation in several marine areas, such as the California Current System (Centurioni et al., 2008), the South China Sea (Centurioni et al., 2009), the Kuroshio Extension (Niiler et al., 2003), the North Pacific (Uchida and Imawaki, 2003) and the Mediterranean Sea (Menna et al., 2012; Poulain et al., 2012). The main advantages of this method are (1) the removal of biases that arise from the irregular sampling of drifters and (2) the enhancement of the accuracy of velocity estimates for coastal areas and mesoscale features.

In this work, the combination of the geostrophic velocities derived from drifter and satellite altimetry is implemented in the BS, so as to describe its surface circulation and its seasonal and interannual variability over the period 19992009. The combined method, applied to concurrent satellite and drifter observations, gives an estimation of the mean dynamic topography (MDT) of the BS in terms of absolute geostrophic velocity field.

A first attempt to estimate a MDT for the BS based on in situ and satellite data was made by Kubryakov and Stanichny (2011), applying the synthetic method described by Rio and Hernandez (2004) and Rio et al. (2007). This synthetic MDT (SMDT) was computed over the period 19931999 using measurements of drifter velocities, hydrological data and along-track sea level anomalies (SLA). The SMDT defines the basin scale RC, two separate cyclonic cells in the western and eastern parts of the BS and some mesoscale and sub-basin-scale features near the periphery of the basin. Anticyclonic mesoscale eddies are located between the continental slope and the coast and can feed the sub-basin-scale eddies (Stanev, 2005); the typical location and evolution of these structures are defined by Staneva et al. (2001) and Korotaev et al. (2003).
The goal of this paper is to produce a regularly sampled data set of the geostrophic currents in the BS, so as to describe quantitatively the pathways and the spatio-temporal variability of the surface circulation in different regions of the basin. The paper is organised as follows: information on drifter, remotely sensed altimetry data and wind products is given in Sect. 2, followed by a description of the methods used to compute the surface geostrophic field. PseudoEulerian statistics, seasonal and interannual characteristics and eddy variability are presented and discussed in Sect. 3 . The main conclusions are summarised in Sect. 4.

\section{Data and methods}

The Lagrangian data used in this study come from 89 satellite-tracked drifters deployed in the BS between 1999 and 2009. The majority are surface velocity program (SVP) drifters, consisting of a surface buoy tethered to a holeysock drogue centred at a depth of $15 \mathrm{~m}$. The others types are coastal ocean dynamic experiment (CODE) drifters, composed of a vertical $1 \mathrm{~m}$-long negative buoyant tube with four radial vanes, and compact meteorological and oceanographic drifters (CMOD) that consist of a $60 \mathrm{~cm}$-long aluminium cylindrical hull drogue with the sonobuoy case. They measure the near-surface currents in the first $15 \mathrm{~m}$ of the water column with various accuracies and errors induced by wind and waves (Poulain et al., 2009). The drifter position time series were edited to remove spikes and outliers and linearly interpolated at $2 \mathrm{~h}$ intervals using the kriging technique (Poulain et al., 2004). The interpolated positions were lowpass filtered (Hamming filter with cut-off period at $36 \mathrm{~h}$ ) to remove high frequency current components and sub-sampled at $6 \mathrm{~h}$ intervals. Velocity components were then estimated from centred finite differences of the $6 \mathrm{~h}$ positions and finally archived in a database (http://doga.ogs.trieste.it/sire/ medsvp/). The pseudo-Eulerian velocity statistics directly computed with the drifter data are defined as "biased" because the drifter data are usually non-uniformly sampled in space and time (Centurioni et al., 2008; Menna et al., 2012; Poulain et al., 2012).

Cross-calibrated, multi-platform (CCMP) ocean surface wind velocities (Atlas et al., 2009) were filtered and interpolated at the drifter locations and times, then used with the drifter velocities in a linear regression model in order to estimate the currents directly (slippage) and indirectly (Ekman currents) induced by the winds $\left(\boldsymbol{U}_{\text {wind-driven }}\right)$. This method has been already applied to estimate the wind-driven currents in the tropical Pacific (Ralf and Niiler, 1999) and in the Mediterranean Sea (Menna et al., 2012; Poulain et al., 2009, 2012). Drifter velocities $(\boldsymbol{U})$ were used to estimate $\boldsymbol{U}_{\text {wind-driven }}$ using the following linear regression model (Poulain et al., 2012):

$\boldsymbol{U}=\beta \boldsymbol{e}^{i \theta} \boldsymbol{W}+$ error $=\boldsymbol{U}_{\text {wind-driven }}+$ error, 
Table 1. Results of the regression model (Eq. 1) applied to extract the wind-driven currents from the velocities of the different types of drifters. $R^{2}$ is the coefficient of determination and $N$ is the number of observations considered.

\begin{tabular}{llrr}
\hline Drifter Type & $\beta e^{i \theta}$ & $R^{2}(\%)$ & $N$ \\
\hline CMOD & $0.01 \exp \left(-25^{\circ} i\right)$ & 20 & 1992 \\
CODE & $0.008 \exp \left(-28^{\circ} i\right)$ & 5 & 4813 \\
SVP & $0.007 \exp \left(-31^{\circ} i\right)$ & 4 & 25732 \\
\hline
\end{tabular}

where $\beta$ is a real constant and $\theta$ is the angle (positive anticlockwise) which represent, respectively, the estimations of intensity and direction of drifter wind-driven currents with respect to the wind velocity; $\boldsymbol{W}$ is the wind velocity interpolated at the drifter locations and times. The model was applied to the different drifter designs separately, over the whole BS, and the results are presented in Table 1. The SVP drifters measured the smallest wind-driven currents, amounting to $0.7 \%$ of the wind speed and directed about $30^{\circ}$ to the right of the wind; these currents represent $4 \%$ of total velocity variance. The CODE drifters show wind-driven currents of $0.8 \%$ of the wind speed with an angle of $28^{\circ}$ to the right of the wind and an explained variance of about $5 \%$. The CMOD drifters move more downwind (about $25^{\circ}$ to the right of the wind) with wind-driven currents amounting to $1 \%$ of the wind speed and explain a significant portion of the velocity variance (about 20\%). The regression coefficients in the BS are similar to those estimated by Poulain et al. $(2009,2012)$ in the Mediterranean Sea. The mean intensity of the ageostrophic current estimated from Eq. (1) in $0.25^{\circ} \times 0.25^{\circ}$ bins is $1.5 \mathrm{~cm} \mathrm{~s}^{-1}$, with maximum values of $\sim 7 \mathrm{~cm} \mathrm{~s}^{-1}$ located in the interior of the basin and in the western region (not shown). Finally, the wind-driven currents estimated from Eq. (1) were subtracted from the drifter velocities to obtain an estimation of the geostrophic components $\boldsymbol{U}_{\mathrm{DG}}\left(\boldsymbol{U}_{\mathrm{DG}}=\boldsymbol{U}-\boldsymbol{U}_{\text {wind-driven }}\right)$. These currents can obviously contain some contribution which is non geostrophic, especially near the coast and in small-scale eddies due to nonlinear effects, but for simplicity and because mean currents will be mostly discussed, we will refer to these currents as geostrophic in this paper. To quantify the contribution of the wind-driven currents to the total drifter velocity, the percentage of total mean kinetic energy of the residuals per unit of mass (eddy kinetic energy; EKE) due to slippage and Ekman currents is computed on a $0.25^{\circ} \times 0.25^{\circ}$ resolution grid (not shown). The removal of Ekman component results in a reduction of the EKE computed from the drifter data set in $80 \%$ of the cases; the mean reduction accounts for $30 \%$ of the total EKE.

The altimetry data used in this work are gridded (oneeight of a degree Mercator projection grid) Ssalto/Duacs daily, multi-mission, delayed time products from AVISO (Ssalto/Duacs users handbook 2013). SLA data are defined with respect to a $7 \mathrm{yr}$ mean (1993-1999). The high spatial resolution of these regional products allow one to discriminate the mesoscale patterns. Because of the intermittent temporal distribution and the scarcity of the drifter data (not shown), daily altimetry products were preferred to weekly products in order to have a larger number of drifter-satellite concurrent observations.

Drifter geostrophic velocities and satellite altimetry data were averaged in non-overlapping geographical bins of $0.25^{\circ} \times 0.25^{\circ} \times 1$ day . The bin-size was chosen as a compromise to resolve the basin and sub-basin (50-100 km) circulation of the BS and also to have a statistically significant number of drifter data inside each bin. Drifter and satellite data were combined in each spatial bin using the following regression model (according to the method described in Poulain et al., 2012):

$\boldsymbol{U}_{\mathrm{DG}}=\boldsymbol{A} \boldsymbol{U}_{\mathrm{SLA}}+\boldsymbol{B}+$ error,

where the vector $\boldsymbol{U}_{\text {SLA }}$ includes the bin-averaged anomalies of surface geostrophic velocities, concurrent with the binaveraged drifter geostrophic velocities $\boldsymbol{U}_{\mathrm{DG}}$. The unknowns $\boldsymbol{A}$ and $\boldsymbol{B}$ are complex numbers or 2-D vectors. The slope $\boldsymbol{A}$ is the local adjustment of amplitude of $\boldsymbol{U}_{\text {SLA }}$ (Niiler et al., 2003). Over the time period considered for the definition of SLA (1993-1999), the mean of $\boldsymbol{U}_{\text {SLA }}$ is zero and $\boldsymbol{B}$ coincides with the time-mean drifter circulation; for any other period, the mean of $\boldsymbol{U}_{\mathrm{SLA}}$ is not zero and $\boldsymbol{B}$ is the offset between $\boldsymbol{U}_{\mathrm{SLA}}$ and $\boldsymbol{U}_{\mathrm{DG}}$ (Menna et al., 2012). The offset $\boldsymbol{B}$ represents the MDT expressed in terms of geostrophic velocities, partly referred to the SLA definition period (1993-1999) and partly referred to the drifter data period (1999-2009). Following Poulain et al. (2012), the slope $\boldsymbol{A}$ was subsequently low-pass filtered in $0.75^{\circ} \times 0.75^{\circ}$ overlapping bins to remove insignificant noise. The vector complex correlation (Kundu, 1976) between $\boldsymbol{U}_{\mathrm{DG}}$ and $\boldsymbol{U}_{\text {SLA }}$ (Fig. 1a) is generally larger than 0.6 in the BS region, supporting the validity of the approach described by Eq. (2); correlation is low west of the Crimean Peninsula and off southern Bulgaria. The magnitude of the low pass filtered $|\boldsymbol{A}|$ and of $\boldsymbol{B}$ are shown in Fig. 1b and c, respectively. The magnitude of $|\boldsymbol{A}|$ varies mostly between 0.5 and 1.5; it exceeds 1.5 in the centre of the BS basin and off the northern coast of Bulgaria. Deviation of $\boldsymbol{A}$ from unity is mainly due to the oversmoothing of the satellite altimeter data, to the existence of residual wind-driven components, non-linear boundary currents and ageostrophic acceleration in the drifter velocities (Niiler et al., 2003; Poulain et al., 2012) and to the limited number of drifter data in the interior of the basin. The veering angle introduced by $\boldsymbol{A}$ (not shown) is not significantly different from zero. The offset $\boldsymbol{B}$ is as large as $30 \mathrm{~cm} \mathrm{~s}^{-1}$ in the fast $\mathrm{RC}$, in particular along the Anatolian and Crimean coasts, and smaller than $5 \mathrm{~cm} \mathrm{~s}^{-1}$ in the interior of the basin. The relationship between drifter velocities and satellite SLA ( $\boldsymbol{A}$ and $\boldsymbol{B})$, derived from $11 \mathrm{yr}$ of concurrent data (1999-2009), can be used to estimate the mean unbiased absolute geostrophic currents $\left\langle\boldsymbol{U}_{\mathrm{G}}\right\rangle_{\mathrm{u}}$ for any 

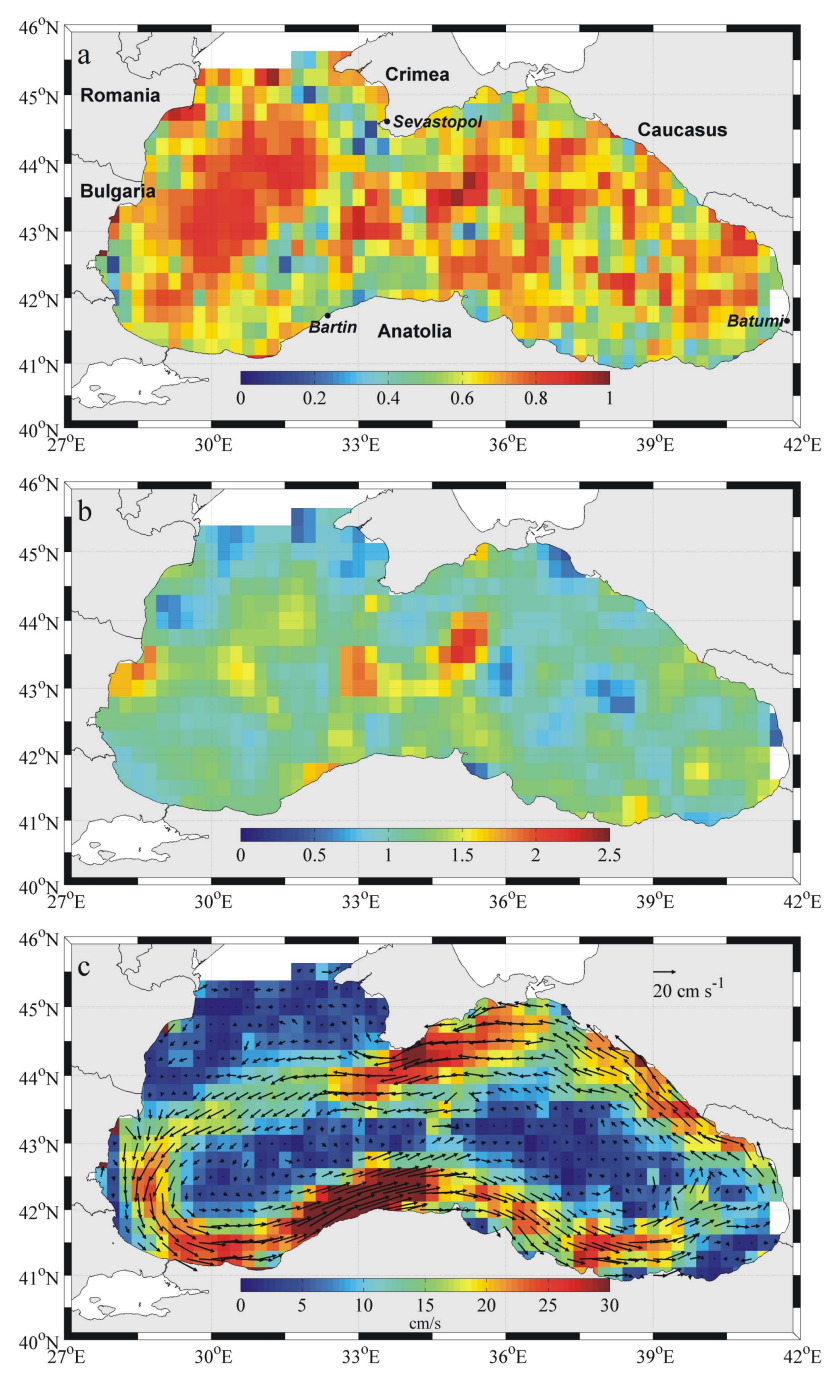

Fig. 1. Spatial distribution of the magnitude of (a) the complex correlation between drifter geostrophic velocities $\boldsymbol{U}_{\mathrm{DG}}$ and satellite anomalies of surface geostrophic velocities $\boldsymbol{U}_{\mathrm{SLA}}$; (b) the low pass filtered slope $|\boldsymbol{A}|$ and (c) the offset $\boldsymbol{B}$ depicted with vectors and colours.

time period in which $\boldsymbol{U}_{\text {SLA }}$ is available, independently from the availability of drifter data:

$\left\langle\boldsymbol{U}_{\mathrm{G}}\right\rangle_{\mathrm{u}}=\boldsymbol{A}\left\langle U_{\mathrm{SLA}}\right\rangle_{\mathrm{u}}+\boldsymbol{B}$,

where $\boldsymbol{U}_{\mathrm{G}}$ are the surface geostrophic currents described by Eq. (2) and \langle\rangle$_{u}$ indicates the "unbiased" temporal averages in each spatial bin. The pseudo-Eulerian statistics computed with these geostrophic currents are defined as "unbiased" because they are less biased with respect to those calculated directly with the drifter data (Menna et al., 2012; Poulain et al., 2012).

The interannual variability of the geostrophic circulation was assessed using the annual maps of kinetic energy of the mean flow per unit mass (MKE) and of EKE. The MKE is defined as

$\mathrm{MKE}=\frac{1}{2}\left(\left\langle U_{\mathrm{G}}\right\rangle_{\mathrm{u}}^{2}+\left\langle V_{\mathrm{G}}\right\rangle_{\mathrm{u}}^{2}\right)$.

The residuals of geostrophic velocity field were evaluated by removing the mean unbiased velocity $\left\langle\boldsymbol{U}_{\mathrm{G}}\right\rangle_{\mathrm{u}}$ from each daily value of $\boldsymbol{U}_{\mathrm{G}}\left(\boldsymbol{U}_{\mathrm{G}}^{\prime}=\boldsymbol{U}_{\mathrm{G}}-\left\langle\boldsymbol{U}_{\mathrm{G}}\right\rangle_{\mathrm{u}}\right)$ and the EKE is defined as the following annual mean:

$\mathrm{EKE}=\frac{1}{2}\left(\left\langle U_{\mathrm{G}}^{\prime 2}\right\rangle_{\mathrm{u}}+\left\langle V_{\mathrm{G}}^{\prime 2}\right\rangle_{\mathrm{u}}\right)$.

The seasonal and interannual variability of mesoscale and sub-basin-scale eddies in the BS was investigated in terms of kinetic energy of geostrophic velocity residuals (KE) per unit of mass, evaluated for each daily value of $\boldsymbol{U}_{\mathrm{G}}^{\prime}$ and defined as

$\mathrm{KE}=\frac{1}{2}\left(U_{\mathrm{G}}^{\prime 2}+V_{\mathrm{G}}^{\prime 2}\right) ;$

Hovmoller diagrams of the KE in the period 1999-2009 were computed along the Anatolia and Crimean-Caucasian coasts.

Finally, the combined data set was used to reconstruct the relative vorticity $(\zeta)$ field associated with the surface circulation in the region of $\mathrm{BE}$ and $\mathrm{SE}$. The relative vorticity was evaluated as the vertical component of the velocity field curl (Pedlosky, 1987):

$\zeta=\frac{\partial \boldsymbol{V}_{\mathrm{G}}}{\partial x}-\frac{\partial \boldsymbol{U}_{\mathrm{G}}}{\partial y}$.

\section{Results and discussion}

The unbiased pseudo-Eulerian velocity statistics (Fig. 1c) depict the well known characteristics of the mean circulation in the upper layer of the BS suggested by several authors in the past (e.g. Korotaev et al., 2001; Poulain et al., 2005), including the RC, BE and SE. However they add new information about the seasonal and interannual characteristics of the surface circulation in the BS. This analysis is focused on the boundary regions characterised by high density of drifter data (Anatolia and Crimea coasts, Batumi and Sevastopol areas).

\subsection{Seasonal variability}

Seasonal variations are emphasised by removing the mean velocity field (Fig. 1c) from the mean seasonal current fields; the resulting anomalies are shown in Fig. 2. Anomalies larger than $8-10 \mathrm{~cm} \mathrm{~s}^{-1}$ are observed in the BE $\left(41-43^{\circ} \mathrm{N}, 39.5-\right.$ $\left.42^{\circ} \mathrm{E}\right)$ and $\mathrm{SE}\left(43.5-45^{\circ} \mathrm{N}, 30.5-32.5^{\circ} \mathrm{E}\right)$ regions and east of the Crimean Peninsula. The cyclonic RC is stronger in winter (mean anomalies of about $4-5 \mathrm{~cm} \mathrm{~s}^{-1}$; maximum values larger than $10 \mathrm{~cm} \mathrm{~s}^{-1}$ along the Anatolia and Crimea coasts and in the BE; Fig. 2a) and weaker in spring/fall (mean anomalies of about $2 \mathrm{~cm} \mathrm{~s}^{-1}$; Fig. 2b, d) and summer (the anticyclonic anomalies of RC indicate that the summer currents 

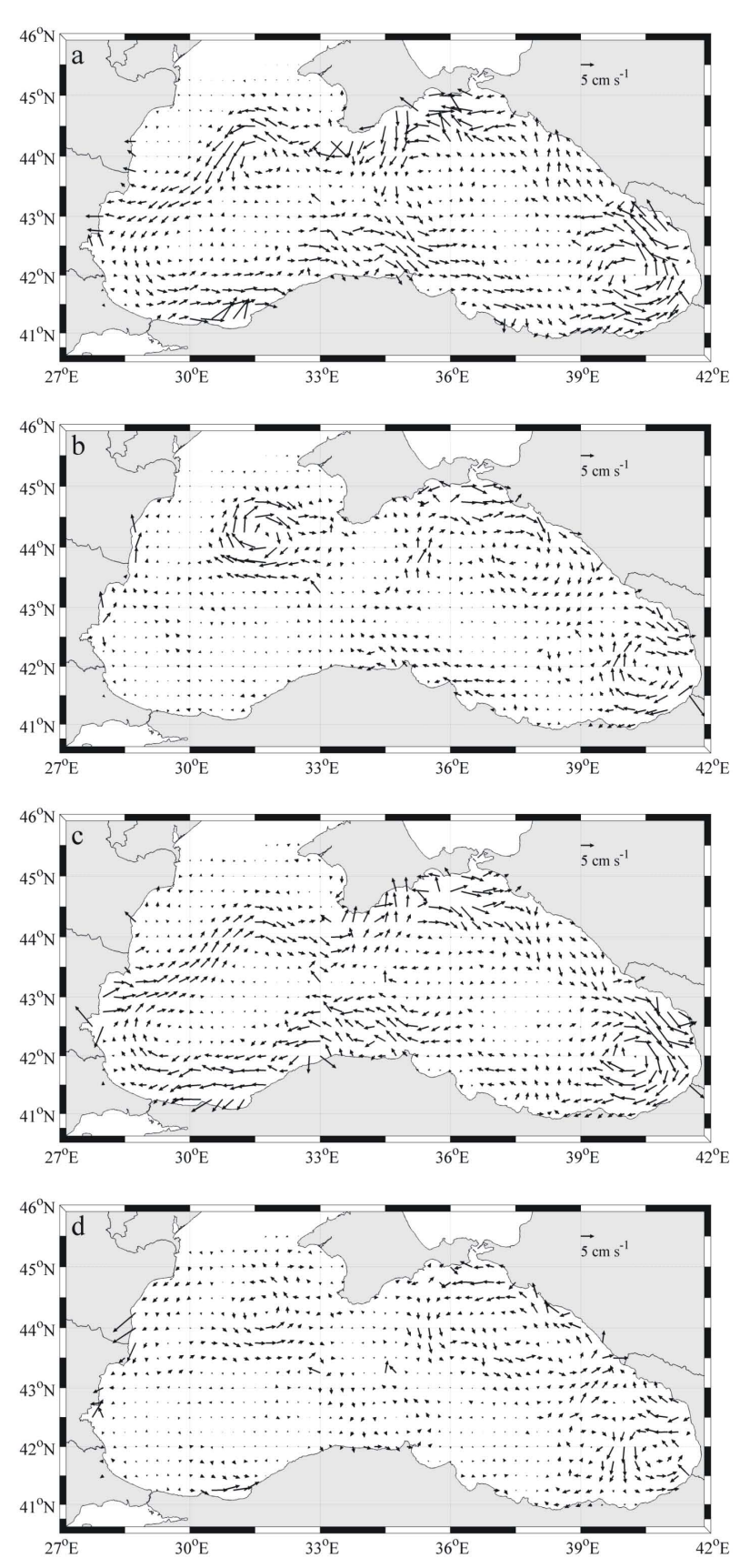

Fig. 2. Unbiased estimates of the anomalies of the mean surface geostrophic circulation in the Black Sea during (a) winter (JanuaryMarch), (b) spring (April-June), (c) summer (July-September), (d) fall (October-December), in spatial bins of $0.25^{\circ} \times 0.25^{\circ}$ and for the period 1999-2009.

are $4-5 \mathrm{~cm} \mathrm{~s}^{-1}$ smaller than the mean currents; Fig. 2c). The $\mathrm{BE}$ is characterised by an intense cyclonic circulation in winter and an anticyclonic circulation in summer; the SE is most intense in spring and shows a less periodic nature than the BE. These results agree well with Stanev et al. (2000) and Poulain et al. (2005).

\subsection{Interannual variability}

\subsubsection{Mean flow}

The MKE computed on a yearly basis is used to describe the annual variation of the mean circulation. The annual maps (Fig. 3) depict a more intense RC circuit in the period 20022006 with speeds of $20-40 \mathrm{~cm} \mathrm{~s}^{-1}$ and MKE larger than $250 \mathrm{~cm}^{2} \mathrm{~s}^{-2}$; maximum values are observed along the Anatolia $\left(600-700 \mathrm{~cm}^{2} \mathrm{~s}^{-2}\right)$ and Crimea $\left(500 \mathrm{~cm}^{2} \mathrm{~s}^{-2}\right)$ coasts. Generally, the northwest branch of the Rim Current is weaker with speeds of $5-15 \mathrm{~cm} \mathrm{~s}^{-1}$ and values of MKE smaller than $150 \mathrm{~cm}^{2} \mathrm{~s}^{-2}$; larger intensities in this area are observed in 2002 and in the period 2005-2006 (speeds of $20-25 \mathrm{~cm} \mathrm{~s}^{-1}$ and MKE larger than $200 \mathrm{~cm}^{2} \mathrm{~s}^{-2}$ ). The RC surrounds two cyclonic structures (described in the previous studies as the Western and Eastern gyres), that show the same characteristics over the whole study period (speeds smaller than $10 \mathrm{~cm} \mathrm{~s}^{-1}$ and MKE smaller than $50 \mathrm{~cm}^{2} \mathrm{~s}^{-2}$ ).

The annual maps of EKE (Fig. 4) reach higher values in the Batumi region (larger than $250 \mathrm{~cm}^{2} \mathrm{~s}^{-2}$ ) in 2002, in the Sevastopol region (larger than $150 \mathrm{~cm}^{2} \mathrm{~s}^{-2}$ ) in 2000 and 2005, and in both these regions in 2003, 2004, 2006 and 2008; in 2003 high energy values are reached also along the western coast of the BS and along the Crimean coast. The regions characterised by the most intense interannual variations are the same as those estimated in Stanev et al. (2000).

\subsubsection{Mesoscale eddies}

Variability of the geostrophic component of the mesoscale $(5-10 \mathrm{~km})$ features in the BS was estimated using the time series of the KE. Mesoscale velocities are mostly included in the velocity variance and in the eddy kinetic energy. In particular, the KE can be used as a good indicator to follow the seasonal and interannual evolution of the mesoscale structures, as its large and variable values coincide with the main locations of the mesoscale eddies along the coasts of the BS (Fig. 5). The Hovmoller diagram in Fig. 5a, computed by meridionally averaging each $\mathrm{KE}$ value between 41 and $42.5^{\circ} \mathrm{N}$, illustrates the interannual changes in intensity and location of the mesoscale eddies off the Anatolia coast $\left(28.5-39^{\circ} \mathrm{E}\right)$. The Bosphorus Eddy is a recurrent structure located near $28-29^{\circ} \mathrm{E}$ with values of KE generally smaller than $200 \mathrm{~cm}^{2} \mathrm{~s}^{-2}$; its energy increases without a specific periodicity (as in March 2001, July 2006, NovemberDecember 2007); sometimes it moves eastward and interacts with the close Sakarya Eddy (August-October 2003, October 2005, January 2006, December 2008-January 2009) reaching $\mathrm{KE}$ values larger than $500 \mathrm{~cm}^{2} \mathrm{~s}^{-2}$. The interaction between the Bosphorus and the Sakarya eddies confirms the description of Korotaev et al. (2003). The Sakarya Eddy, located around $31^{\circ} \mathrm{E}$, prevails only in some years $(2000$, 2002, 2003, 2005, 2006, 2009) with KE values larger than $250 \mathrm{~cm}^{2} \mathrm{~s}^{-2}$. Figure $5 \mathrm{a}$ shows the presence of another eddy 


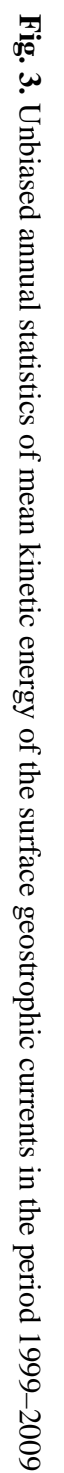
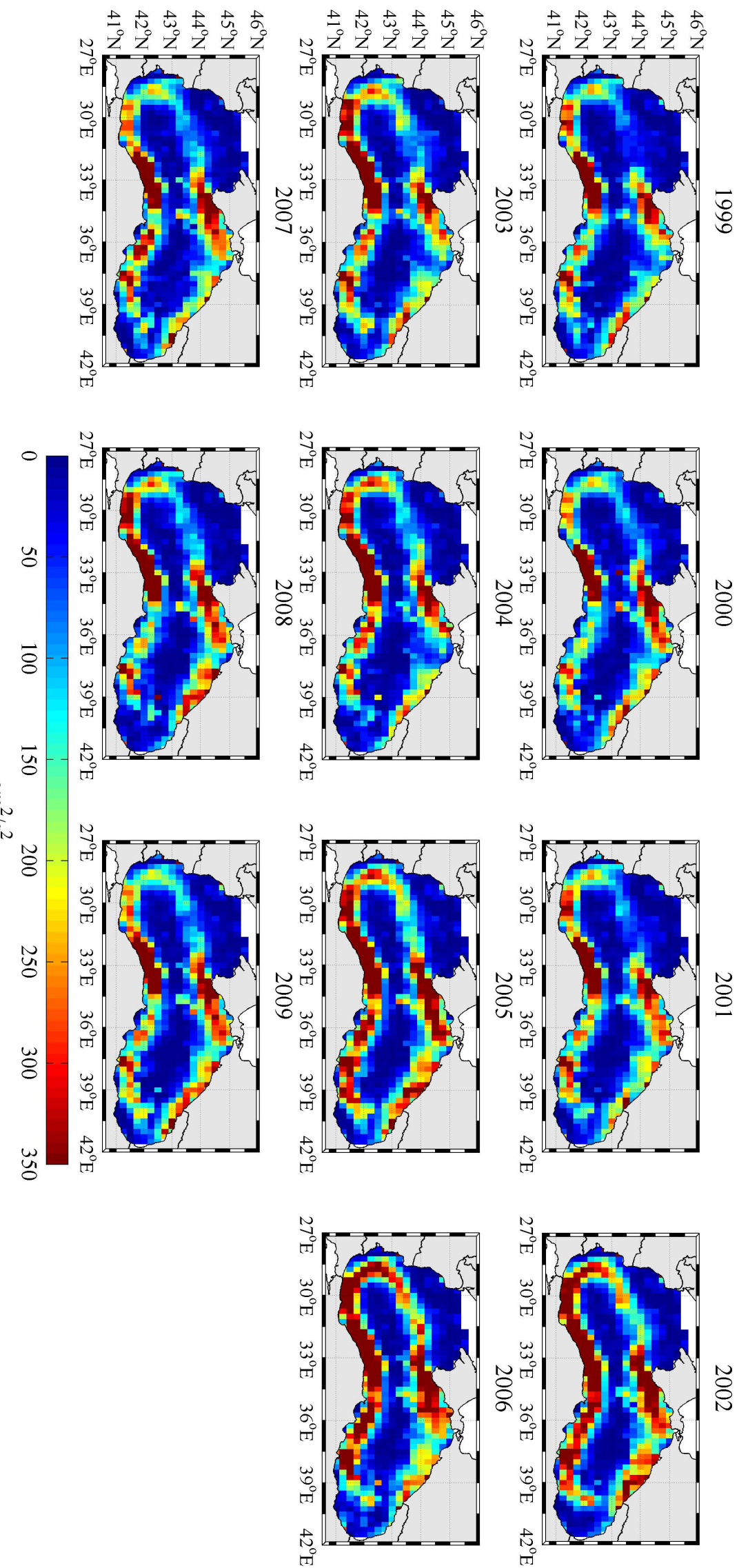

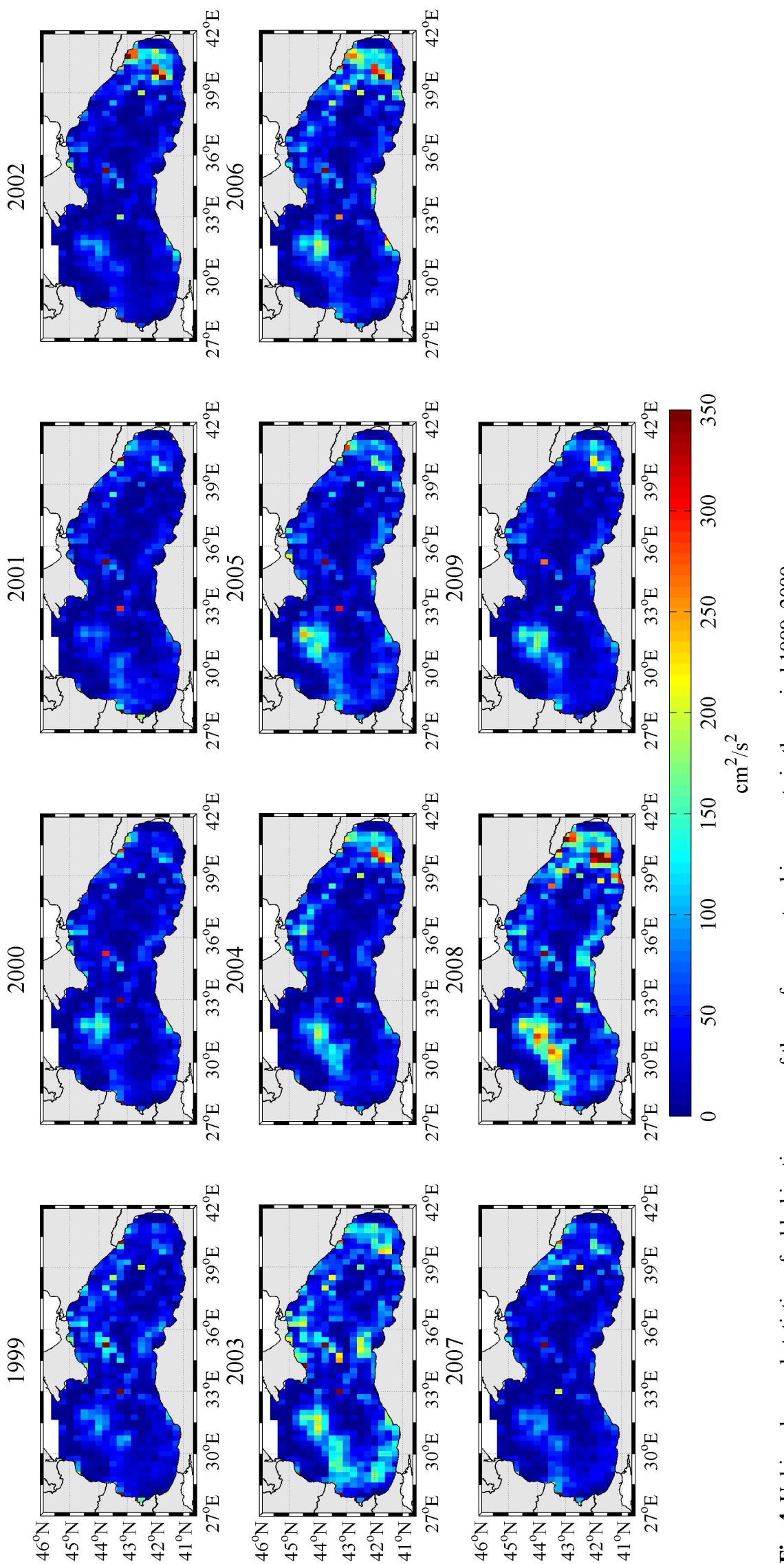

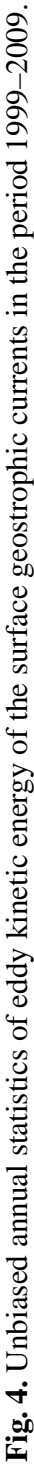




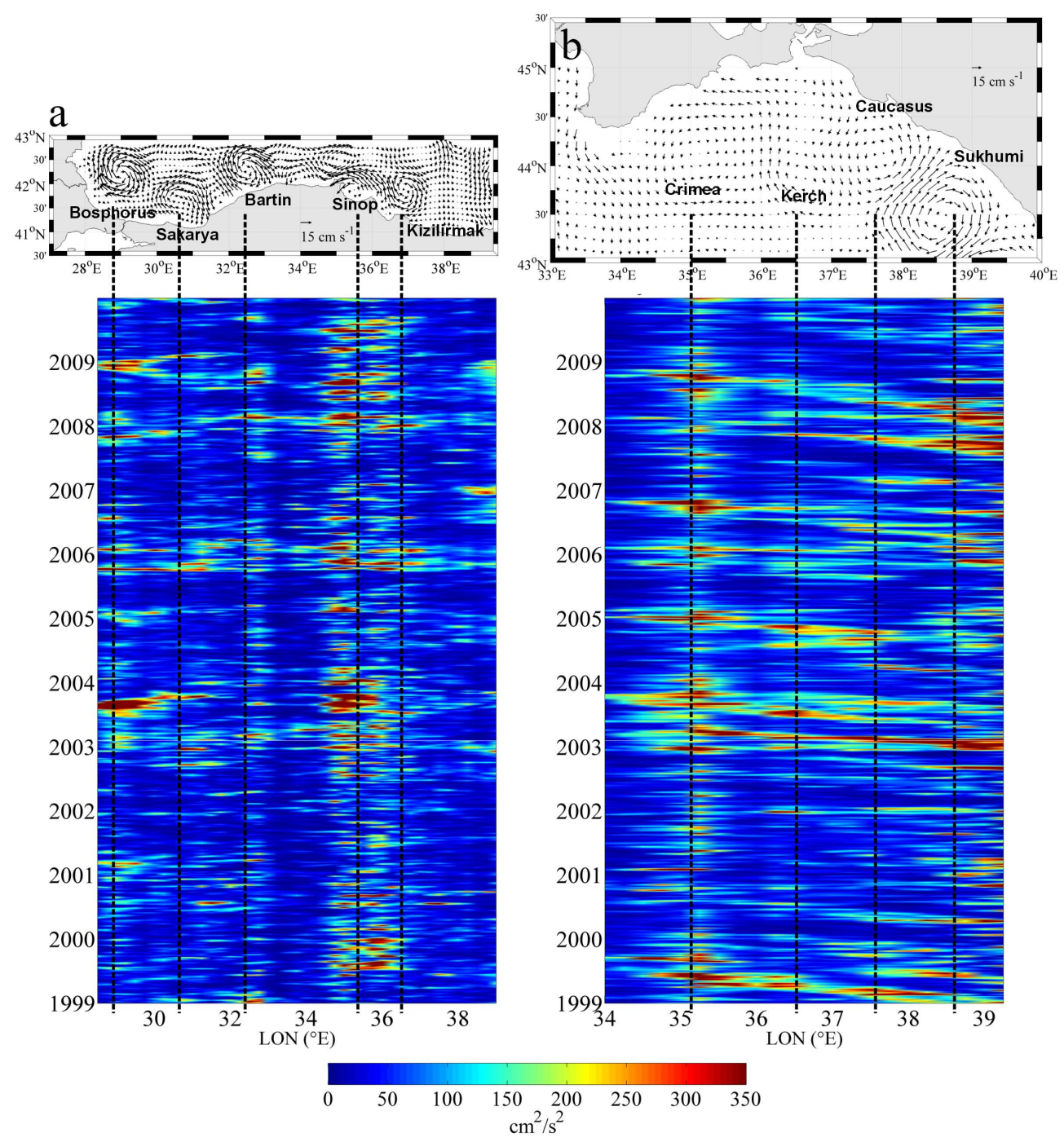

Fig. 5. Hovmoller diagrams of KE over the (a) Anatolia and (b) Crimea-Caucasus coasts. In the upper panels daily snapshots of the anomalies of surface geostrophic velocities (3 May 2001 and 15 January 1999, respectively) indicate the location of the main eddies along the BS coasts; these anomalies are depicted with the original spatial resolution of AVISO products (of one-eighth of a degree) in order to better discriminate the mesoscale structures. Dashed lines mark the locations of mesoscale eddies.

between 32 and $33^{\circ} \mathrm{E}$ with a quasi-persistent nature and KE signal between 150 and $250 \mathrm{~cm}^{2} \mathrm{~s}^{-2}$; this structure can move westward and interact with the Sakarya Eddy (2005-2006). A mesoscale feature in this area was already recognised by Korotaev et al. (2003); according to its geographical location along the coast of the Bartin Province we define this structure as the Bartin Eddy. The Sinop and Kizilirmak Eddies, located between 34.5 and $37^{\circ} \mathrm{E}$, show a quasi-permanent nature, in contrast with the results of Korotaev et al. (2003), and high values of $\mathrm{KE}\left(200-600 \mathrm{~cm}^{2} \mathrm{~s}^{-2}\right)$ throughout the period considered; the highest KE signal is observed in the period August-October 2003 in concomitance with the maximum intensities of the Bosphorus Eddy.

The diagram in Fig. 5b, computed by meridionally averaging each $\mathrm{KE}$ value between 43.5 and $45^{\circ} \mathrm{N}$, includes the
Caucasus coast and the eastern side of the Crimean Peninsula $\left(34-39.25^{\circ} \mathrm{E}\right)$. The Crimea Eddy is a quasi-permanent mesoscale feature, located between 34.5 and $35.5^{\circ} \mathrm{E}$, characterised by a pronounced interannual variability in terms of $\mathrm{KE}$ and a zonal extension of the eddy. The KE signal shows generally higher values (larger than $500 \mathrm{~cm}^{2} \mathrm{~s}^{-2}$ ) when the Crimea Eddy becomes larger $(1999,2003,2006,2008)$. Another mesoscale eddy, identified by Korotaev et al. (2003) as the Kerch Eddy, is located between 36 and $37^{\circ} \mathrm{E}$ (KE values of $250-400 \mathrm{~cm}^{2} \mathrm{~s}^{-2}$ ); it occurs sporadically and persists for a few months. The Caucasus Eddy, located around $37-38^{\circ} \mathrm{E}$, is a sporadic structure with a KE larger than $200 \mathrm{~cm}^{2} \mathrm{~s}^{-2}$ that occurs in the same periods as the Kerch Eddy, with which it sometimes interacts $(2003,2004,2006,2007)$. The interactions among the Kerch Eddy, the Caucasus Eddy and the 

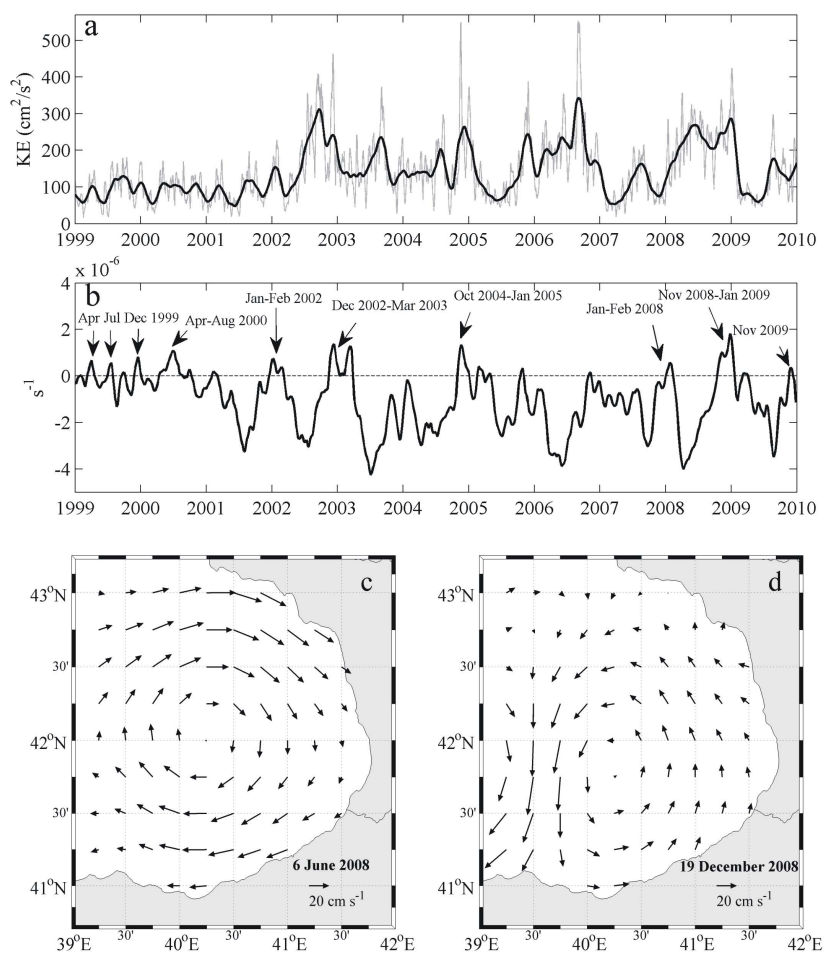

Fig. 6. (a) Time series of KE spatially averaged in the region of $\mathrm{BE}\left(41-43^{\circ} \mathrm{N}, 39-42^{\circ} \mathrm{E}\right)$; grey line represents the daily time series while the black line is the 90 day moving average of KE. (b) Time series of the spatially averaged relative vorticity of the surface geostrophic currents in the region of BE; black arrows emphasise the main periods of cyclonic circulation. Snapshots of the (c) anticyclonic and (d) cyclonic circulation $\left(\boldsymbol{U}_{\mathrm{G}}\right)$ over the Batumi area.

RC confirm the previous results of Korotaev et al. (2003) while their temporal intermittence contradicts Korotaev et al. (2003). The Sukhumi Eddy $\left(38.5-39.25^{\circ}\right.$ E) reveals a quasi-permanent nature with greater intensities during the winter and fall months (KE values of $200-400 \mathrm{~cm}^{2} \mathrm{~s}^{-2}$ ); it merges with the close Caucasus Eddy in winter 2003, fall 2007 and winter-spring 2008. The continual occurrence of the Sukhumi Eddy contradicts the results of Korotaev et al. (2003).

\subsubsection{Sub-basin-scale eddies}

The variability of the major sub-basin structures in the BS (the $\mathrm{BE}$ and the $\mathrm{SE}$ ) is investigated using the spatially averaged time series of KE (Figs. 6a, 7a) computed in the eddy regions. The BE is more intense in 2002-2006 and 2008 with typical values of KE between $200 \mathrm{~cm}^{2} \mathrm{~s}^{-2}$ and $300 \mathrm{~cm}^{2} \mathrm{~s}^{-2}$ (Fig. 6a); this structure is usually characterised by a diameter of $\sim 100 \mathrm{~km}$ and is located in the southeast corner of the BS. The activity of BE is weaker in the period 1999-2001 and 2007 (Fig. 6a). The pronounced interannual variability in the Batumi region confirms the results of the model simulations of Staneva et al. (2001). Reversals of the surface circulation
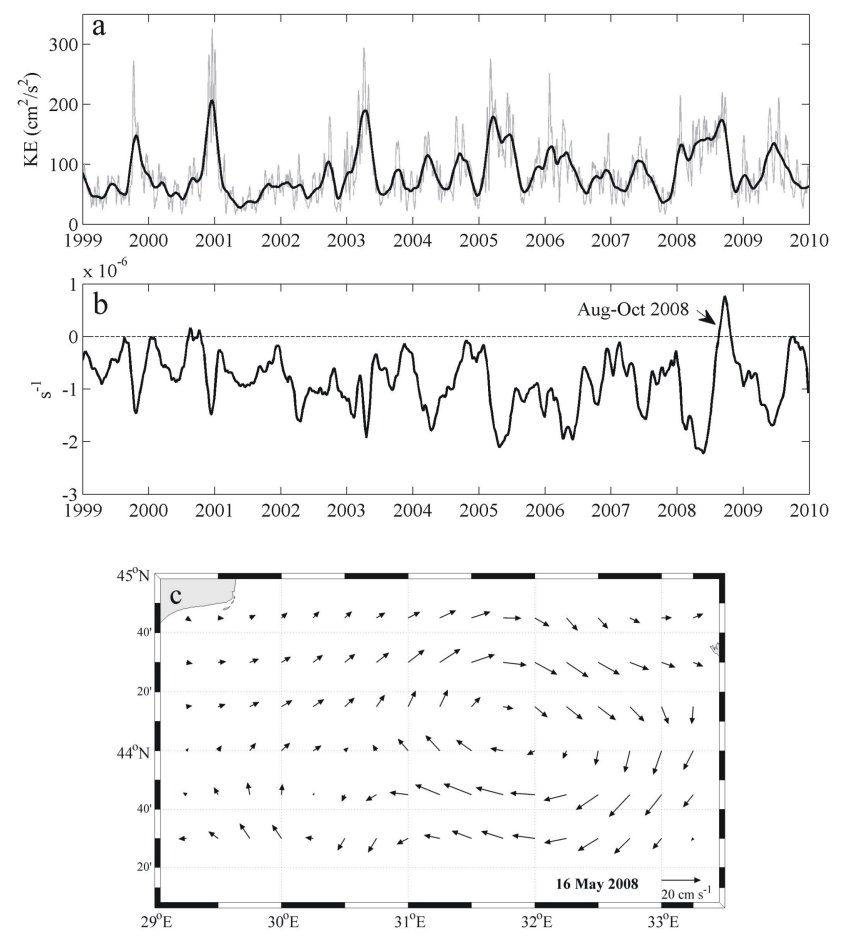

Fig. 7. (a) Time series of KE spatially averaged in the region of $\mathrm{SE}\left(43.75-44.75^{\circ} \mathrm{N}, 30-33^{\circ} \mathrm{E}\right)$; grey line represents the daily time series while the black line is the 90 day moving average of KE. (b) Time series of the spatially averaged relative vorticity of the surface geostrophic currents in the region of SE; black arrow indicate the period characterised by cyclonic circulation. (c) Snapshot of geostrophic currents $\left(\boldsymbol{U}_{\mathrm{G}}\right)$ in the region of SE.

in the Batumi region are documented using the time series of the spatially averaged $\zeta$ (Fig. 6b). The typical anticyclonic pathway, characterised by negative vorticity values, is sometimes interrupted by a cyclonic regime (positive vorticity). The main cyclonic circulation events are observed in springsummer 2000, winters 2002 and 2003, fall 2004-early winter 2005, fall 2008-early winter 2009 (black arrows in Fig. 6b). High values of KE correspond to anticyclonic rotation. Examples of anticyclonic and cyclonic regimes are shown in Fig. $6 \mathrm{c}$ and $d$, respectively.

The SE is characterised by low energy levels with respect to the BE (Fig. 7a); the maximum mean value of $\mathrm{KE}$ $\left(\sim 300 \mathrm{~cm}^{2} \mathrm{~s}^{-2}\right)$ is observed in fall 2000. During the period 2003-2007 the SE shows a pronounced seasonal variability, with higher KE in spring and fall and lower KE in winter and summer. The activity of SE is weaker in 2001-2002 and more intense in 2008. The time series of the spatially averaged $\zeta$ (Fig. 7b) show that the SE is always anticyclonic, except for a cyclonic event in summer-fall 2008 probably due to the intrusion of an RC cyclonic meander in the Sevastopol region. The generation of SE is related to the meandering of the RC in the Sevastopol area and is generally observed in spring (speeds of about $15-20 \mathrm{~cm} \mathrm{~s}^{-1}$; Fig. 7c). 


\section{Conclusions}

The surface geostrophic circulation in the BS has been described combining $11 \mathrm{yr}$ (1999-2009) of drifter and satellite altimetry data in order to construct a regularly sampled data set of observations. Velocity statistics computed from this data set are defined as "unbiased" because they are less biased with respect to those calculated directly with the drifter data. The unbiased pseudo-Eulerian statistics are used to define seasonal and interannual variations of the mean field and of the sub-basin and mesoscale eddies. Mean geostrophic currents obtained in the present work (Fig. 1c) are based on a larger number of in situ drifter observation compared with those estimated from the SMDT of Kubryakov and Stanichny (2011).

Seasonal maps confirm the results of Stanev et al. (2000) and Poulain et al. (2005) and add new information about the $\mathrm{SE}$, which is generated in spring from a meander of the RC (Fig. 2b). The most pronounced seasonal variabilities are located in the RC and in the $\mathrm{BE}$ areas, with anomalies of 8$10 \mathrm{~cm} \mathrm{~s}^{-1}$ with respect to the mean geostrophic field (Fig. 2).

The most intense interannual variations are located in the Batumi and Sevastopol regions (EKE levels larger than $200 \mathrm{~cm}^{2} \mathrm{~s}^{-2}$ ), in good agreement with the results of Stanev et al. (2000) and Staneva et al. (2001). Reversals of the surface circulation in the Batumi region, from anticyclonic to cyclonic regimes, are usually observed in fall-winter; the cyclonic pattern generally persists for periods of 2-4 months.

The analysis of mesoscale eddies along the Anatolia and Crimea-Caucasus coasts expands the results of Korotaev et al. (2003), as describes the interaction between the Sinop and the Kizilirmak eddies (Anatolia) and among the Kerch, the Caucasus and the Sukhumi eddies (Caucasus) and resolves a new quasi-persistent eddy generated along the Anatolia coast and defined as the Bartin Eddy.

Acknowledgements. The authors would like to thanks all the people who deployed drifters in the Black Sea. The altimeter products were produced by SSALTO/DUACS and distributed by AVISO, with support from CNES (http://www.aviso.oceanobs.com/duacs/).

We thank E. Stanev, A. A. Kubryakov and the two anonymous reviewers for their constructive comments on the discussion paper.

Edited by: J. M. Huthnance

\section{References}

Atlas, R., Ardizzone, J. V., Hoffman, R., Jusem, J. C., and Leidner, S. M.: Cross-calibrated, multi-platform ocean surface wind velocity product (MEaSUREs Project), Guide Document, Physical Oceanography Distributed Active Archive Center (PO.DAAC), JPL, Pasadena, California, Version 1.0., 26 pp., 2009.

Centurioni, L. R., Ohlmann, J. C., and Niiler, P. P.: Permanent meanders in the California Current System, J. Phys. Oceanogr., 38, 1690-1710, doi:10.1175/2008JPO3746.1, 2008.
Centurioni, L. R., Niiler, P. N., and Lee, D.-K.: Near surface circulation in the South China Sea during the winter monsoon, Geophys. Res. Lett., 36, L06605, doi:10.1029/2008GL037076, 2009.

Korotaev, G. K., Saenko, O. A., and Koblinsky, C. J.: Satellite altimetry observations of the Black Sea level, J. Geophys. Res., 106, 917-933, doi:10.1029/2000JC900120, 2001.

Korotaev, G., Oguz, T., Nikiforov, A., and Koblinsky, C.: Seasonal, interannual, and mesoscale variability of the Black Sea upper layer circulation derived from altimeter data, J. Geophys. Res., 108, 3122, doi:10.1029/2002JC001508, 2003.

Kubryakov, A. A. and Stanichny, S. V.: Mean Dynamic Topography of the Black Sea, computed from altimetry, drifter measurements and hydrology data, Ocean Sci., 7, 745-753, doi:10.5194/os-7745-2011, 2011.

Kundu, P. K.: Ekman veering observed near the ocean bottom, J. Phys. Oceanogr., 6, 238-242, 1976.

Menna, M., Poulain, P.-M., Zodiatis, G., and Gertman, I.: On the surface circulation of the Levantine sub-basin derived from Lagrangian drifter and satellite altimetry data, Deep-Sea Res., 65, 46-58, doi:10.1016/j.dsr.2012.02.008, 2012.

Niiler, P. P., Maximenko, N. A., Panteleev, G. G., Yamagata, T., and Olson, B. D.: Near-surface dynamical structure of the Kuroshio Extension, J. Geophys. Res.-Oceans, 108, 3193, doi:10.1029/2002JC001461, 2003.

Oguz, T., La Violete, P. E., and Unluata, U.: The upper layer circulation of the Black Sea: Its variability as inferred from hydrographic and satellite observations, J. Geophys. Res., 97, 1256912584, 1992.

Pedlosky, J.: Geophysical Fluid Dynamics, 2nd Edn., 710 pp., Springer, New York, 1987.

Poulain, P.-M., Barbanti, R., Cecco, R., Fayes, C., Mauri, E., Ursella, L., and Zanasca P.: Mediterranean surface drifter database: 2 June 1986 to 11 November 1999, Rel. 75/2004/OGA/31, OGS, Trieste, Italy (CDRom), 2004.

Poulain, P.-M., Barbanti, R., Motyzhev, S., and Zatsepin, A.: Statistical description of the Black Sea near-surface circulation using drifter in 1999-2003, Deep-Sea Res.-Pt. I, 52, 2250-2274, doi:10.1016/j.dsr.2005.08.007, 2005.

Poulain, P.-M., Gerin, R., Mauri, E., and Pennel, R.: Wind Effects on Drogued and Undrogued Drifters in the Eastern Mediterranean, J. Atmos. Ocean Tech., 26, 1144-1156, 2009.

Poulain, P.-M., Menna, M., and Mauri, E.: Surface geostrophic circulation of the Mediterranean Sea derived from drifter and satellite altimeter data, J. Phys. Oceanogr., 42, 973-990, doi:10.1175/JPO-D-11-0159.1, 2012.

Ralph, E. A. and Niiler, P. P.: Wind driven currents in the tropical Pacific, J. Phys. Oceanogr., 29, 2121-2129, 1999.

Rio, M.-H. and Hernandez, F.: A mean dynamic topography computed over the world ocean from altimetry, in-situ measurements, and a geoid model, J. Geophys. Res., 109, C12032, doi:10.1029/2003JC002226, 2004.

Rio, M.-H., Poulain, P.-M., Pascual, A., Mauri, E., Larnicol, G., and Santoleri, R.: A Mean Dynamic Topography of the Mediterranean Sea computed from altimetric data, in-situ measurements and a general circulation model, J. Mar. Syst. 65, 484-508, doi:10.1016/j.jmarsys.2005.02.006, 2007.

Shapiro, G. I., Stanichny, S. V., and Stanychna, R. R.: Anatomy of shelf-deep sea exchanges by a mesoscale eddy in the North West 
Black Sea as derived from remotely sensed data, Remote Sens. Environ., 114, 867-875, 2010.

Stanev, E. V.: Understanding Black Sea Dynamics: overview of recent numerical modelling, Oceanography, 18, 52-71, 2005.

Stanev, E. V., Le Traon, P. Y., and Peneva, E. L.: Sea level variations and their dependency on meteorological and hydrological forcing: Analysis of altimeter and surface data for the Black Sea, J. Geophys. Res., 105, 17203-17216, 2000.
Staneva, J. V., Dietrich, D. E., Stanev, E. V., and Bowman, M. J.: Rim current and coastal eddy mechanisms in an eddy-resolving Black Sea general circulation model, J. Mar. Syst., 31, 137-157, 2001.

Uchida, H. and Imawakki, S.: Eulerian mean surface velocity field derived by combining drifter and satellite altimetry data, Geophys. Res. Lett., 30, 1229, doi:10.1029/2002GL016445, 2003. 